\title{
Impact of user involvement on design students' motivation and self-confidence
}

\author{
Peter D. Conradie ${ }^{1}$ (D) $\cdot$ Bram B. Van Acker ${ }^{2} \cdot{\text { Ellen De } \text { Vos }^{2} \cdot \text { Jelle Saldien }}^{2}$
}

Accepted: 13 June 2019

(c) Springer Nature B.V. 2019

\begin{abstract}
Involvement of users in the design process is generally viewed favourably, both within academia and industry. Their involvement can be seen as a strategy for designers to clarify their design task and reduce uncertainties in the design process. Simultaneously, there is a lack of understanding about the impact that user involvement has on students and how they experience doing so. This paper reports on a study where students were asked to self-report their motivation and self-confidence throughout a design exercise, stretching 11 days, with surveys repeating daily. Additionally, students were asked to indicate which - if any-strategies of user involvement they used every day. We find that students self-reported motivation did not change statistically significantly, while self-confidence did change. However, in neither case did student's involvement of end-users impact how motivated or self-confident they were. We discuss our results in relation to existing research on method use in general and user involvement in particular and conclude with some suggestions for future work.
\end{abstract}

Keywords User involvement $\cdot$ Design education $\cdot$ Design methods

\section{Introduction}

Involving users when designing new products or systems is widely taught and advocated, both in academia (Bano and Zowghi 2014; Kaulio 1998; Kujala 2003; Wormald 2011) and industry (Zoltowski et al. 2012). Nonetheless, little is known about the impact that user involvement has on student's own experience throughout a design exercise.

As a method-defined as any procedures, techniques, aids or 'tools' for designing (Cross 2008, p. 46) —user involvement can be viewed as a strategy to reduce the uncertainty inherent in design. For example, seminal textbooks such as work from Pahl et al. (2007, p. 77) include recommendations to identify "client problems", while work from Sanders and Stappers (2013) discuss several generative methods to elicit requirements from users.

\section{Peter D. Conradie}

peter.conradie@ugent.be

1 imec-mict-UGent, De Krook, Miriam Makebaplein 1, 9000 Ghent, Belgium

2 Department of Industrial Systems Engineering and Product Design, Faculty of Engineering and Architecture, Ghent University, Campus Kortrijk, Graaf Karel de Goedelaan 5, 8500 Kortrijk, Belgium 
More specifically within design engineering education, scholars have emphasised the value of user involvement during the initial stages of new product development (Wormald 2011), and studied the impact that user involvement might have on the student's results (Conradie et al. 2017). The value of user involvement on design outcomes have been the subject of various empirical studies, with researchers generally stressing the positive impact that involving users can have on design outcomes (Bano and Zowghi 2014; Kaulio 1998; Kujala 2003).

However, while these studies aim to cement the value of user involvement on the outcomes of design activities, there is still a limited understanding of how user involvement impacts designers. In this paper, we heed the calls for a better understanding of how designers experience methods (Gerber and Carroll 2012) and more generally a better understanding of design practice (Dorst 2008; Günther and Ehrlenspiel 1999). Beyond this, scholars have identified low uptake of methods in industry-which includes methods for user involvement (Araujo et al. 1996; De Waal and Knott 2016; Mao et al. 2005). Given user involvement's prominence within design as potential remedy for ill-conceived products, (Norman 2013, p. 8), we additionally view it as a relevant topic of inquiry.

\section{Background}

\section{Design, uncertainty and methods}

Design is an act of learning (Beckman and Barry 2007; Dubberly and Evenson 2011). Through designing, new knowledge is created. As with learning, this entails uncertainty, often without precise instructions (Lawson and Dorst 2009). Methods, in turn, serve to assist designers in dealing with uncertainty, by giving them ways to simplify complex design challenges (Cross 2008, p. 46). This might range from efforts to gather information through interviews, developing products through prototyping (Gerber 2009), to heuristic evaluation of a developed artefact (Hanington and Martin 2012).

Given the significance of the early phases of product development, it is important that design students are equipped to face the challenges of uncertainty they may encounter during this stage (Hanington 2003; Wormald 2011). To achieve this, students are taught various methods that aid or assist them in their design task.

\section{Involving users as method}

Important texts such as those from Cross (2008, p. 104) or Pahl et al. (2007, p. 77) propose user involvement as one way of creating better design outcomes, while practical texts such as those by Sanders and Stappers (2013) introduce a variety of methods that can be used by students to generate designs, often while involving users. The International Organization for Standardization (ISO) norm 9241-210 also proposes the Explicit understanding of users, tasks and environments and User-centred evaluation driven/refined design (ISO 2015). More specifically, the ISO norm emphasises benefits of a human centred design approach, ranging from direct benefits such as improving the user experience and productivity, to more indirect benefits including increased brand image. To achieve this it is important that designers use a variety of techniques that can aid them in empathising with their end-users (Giacomin 2014), with the ISO norm noting the importance of methods to involve end users [also see ISO/TR 16982 (2002)]. This in-turn aligns with the idea 
that user involvement can be viewed as an important strategy for successful products, i.e.: reducing the uncertainty inherent in design.

Typical strategies may include focus groups (Denton and McDonagh 2003), or the creation of personas from observations or user research. These methods are aimed at supporting the creation of innovative concepts (Pahl et al. 2007). Users can give designers knowledge and expertise they lack, while also providing contextual information about product use (Klapwijk and Van Doorn 2015). While not exhaustive, Abras et al. (2004) propose several strategies for user-centred design (i.e.: involving users), which include background interviews, focus groups, observations, role playing, testing and questionnaires. In this sense, the authors take a slightly broader view on what composes user involvement than Ball and Ormerod (2000), who frames user involvement as applied ethnography (see also Button 2000).

Additionally, Zoltowski et al. (2012) argues that international design firms such as IDEO are stressing how human centred design contributes to their success [see also IDEO's freely available toolkit (2018)]. Massive Open Online Courses (MOOCs) by platforms such as Coursera are also offering courses in Human Centered Design (Klemmer and Coursera 2019), where there is an emphasis on understanding and involving end users.

Given this focus on users, there have also been studies on the impact of user involvement on system success. Kujala (2003) notes a host of studies that illustrate how user involvement might benefit system outcomes, ranging from increased sales (Karat 1994) to more user productivity (Karat 1997). Earlier work by Baroudi et al. (1986) further emphasise the value of user involvement, with the authors concluding that system user satisfaction increases when users are involved. In the domain of service design, Trischler et al. found that codesign efforts result in outcomes that score higher in user value, but a the cost of reducing feasibility (Trischler et al. 2018), while in the design of business models, Tolkamp et al. argues that user-centred design leads to both incremental and radical business model innovation (Tolkamp et al. 2018).

Beyond design, educational research has studied how student confidence might be increased. For example, in the domain of healthcare Barnett et al. (2016) studied the impact of virtual case presentation as opposed to a written scenarios on student confidence, finding increased student engagement. Similarly, Wood and Wilson-Barnett (1999) found that user involvement resulted in nurses emphasising more with patients. A meta-analysis by Morgan and Jones (2009) find that both students and patients benefit from user involvement. However, the authors also note that user involvement failed to change behaviour in practice. As of yet, to our knowledge, no similar research on user involvement has been conducted within the design education domain.

More recent work by Bano and Zowghi (2014) is more equivocal about user involvement and system success, noting that out of 87 studies analysed, 12 suggested a negative contribution and 23 were uncertain. Nonetheless, the authors conclude that user involvement has a positive impact on system success.

Centrally then, there is the expectation that a human-centered design strategy through user involvement will have positive outcomes on the designed artefact (Abras et al. 2004), with online MOOC Coursera stating that their course on Human Centered Design will help students learn how to design technologies that bring people joy, rather than frustration (Klemmer and Coursera 2019). In The Design of Everyday Things, Norman emphasises this point by proposing human centred design as the antidote to the ill-designed artefacts we encounter daily (2013, p. 8). Giacomin notes that human centred design leads to products, systems and services which are physically, perceptually, cognitively and emotionally intuitive (2014). Other researchers have highlighted the impact of user involvement on 
designers noting the emergence of a more solution-oriented discourse (Rapanta and Cantoni 2014). Thus, both from the perspective of academia and practice, the involvement of end-users is viewed favourably.

\section{Uncertainty, motivation and self-confidence}

As the preceding results indicate, there is a broad consensus on the value of user involvement on design outcomes. However, despite this broad advocacy for user involvement, research also shows that uptake of design methods in industry is limited (Araujo et al. 1996; De Waal and Knott 2016), which includes user centred design methods (Mao et al. 2005).

Additionally, there is a limited understanding of how involvement of users' impacts a designer's own experience during a design exercise. In this, our view aligns with Daalhuizen et al. (2014) who argued that it is paramount to understand designer's experience of methods. More to the point, Gerber and Carroll (2012) contends that existing research has often focussed on the outcomes of several design practices, but few scholars have considered how people feel when engaging in these popular design practices, going further to propose more studies outside the laboratory context. Even earlier, Günther and Ehrlenspiel (1999) also suggested more research on design experience, stressing tendencies to give up and ways of coping with failure as avenues of research, with subsequent potential impacts on design outcomes, including solution creativity or technical quality.

For user involvement, we refer to studies introduced earlier that suggest that user involvement is associated with system success (Bano and Zowghi 2014; Ives and Olson 1984; Kujala 2003). By extension, we hypothesise that user involvement will impact the subjective experience of a design activity, focussing both on their motivation and self-confidence. Analogous to Gerber and Carroll's (2012) argument that through lo-fi prototyping practitioners experience increased confidence and motivation to act we posit that through the involvement of users, both self-confidence and motivation will increase, specifically because it deals with the uncertainties associated with design.

Given this, we propose $\mathrm{H} 1$ and $\mathrm{H} 2$ :

H1 User involvement has a positive impact on student's self-reported motivation

H2 User involvement has a positive impact on student's self-reported self-confidence

Beyond this, we also control for our participants age and level of experience. Atman et al. (2007), based on a suggestion by Cross (2004) considered at least 10 years of practical expertise to be considered an expert. Given that our sample consists mostly of design students in the third year of their bachelor's degree, the distinction between novice and expert designer is not useful. However, because our sample did contain a selection of students with no formal design education, we used this as a control variable.

Finally, we also consider that students will have varying degrees of interest in the design task. The level of affinity might thus also be associated with their self-reported motivation and self-confidence. We will discuss these measures in more detail in the following section. 


\section{Method}

\section{Research setting}

Together with participants from other campuses and education programs, students engage yearly during an intense two-week period with a preselected assignment around a general theme. This year, the focus was sport and wellbeing, with partners from industry. A typical example is the development of an interactive basketball ring, incorporating individual athlete feedback through a wearable device (see Fig. 1), or an interactive gaming mat for rehabilitation purposes.

Students were a mix between third year bachelor students from both professionally oriented design programs and academic industrial engineering programs. All were currently in the final year of their Bachelor level education. However, the group also included some students with more seniority and experience. All groups contained a mix of local and international students. Finally, design students were joined by several students from a sports and movement professional bachelor study program.

With regards to user involvement, users were typically more involved as subjects, rather than partners in design (see Sanders and Stappers 2013). Generally, this entailed efforts such as one-on-one interviews, focus groups, user tests or contextual inquiry, followed by informal user tests. Input gathered from users were subsequently incorporated in the results.

\section{Instrument}

All scales for this study derive from an instrument developed by Daalhuizen et al. (2014). Questions can be viewed in "Appendix". Students were asked to complete a series of questionnaires throughout their two-week project (seven in total). To track students, they were given a random unique personal ID at the start of the study (day 1). They were asked to provide the ID whenever they filled out their survey. The ID was not connected to their names or

Fig. 1 Line drawing of a wearable wristband, conceived during the design exercise

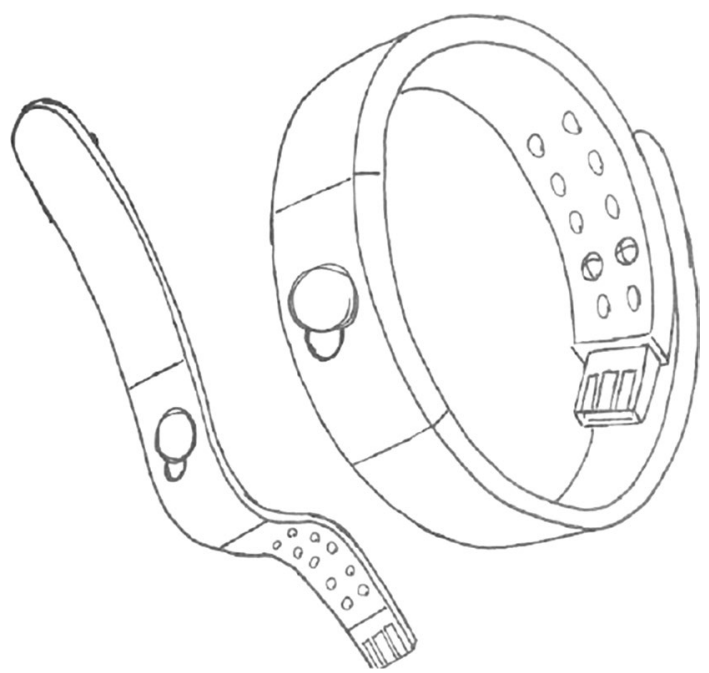


university identification. Given that our participants came from a variety of countries (Spain, United Kingdom, Latvia, The Netherlands, Sweden, China and Belgium) we conducted the survey in English which was only the native language of a minority of participants. Survey A was distributed at the start of the assignment, after the kickoff and Survey B at six predefined moments throughout the two-week period (day 2-day 7). Figure 2 displays an overview of days, different surveys used and key moments.

Survey A questioned students about their interest in the assignment (Daalhuizen et al. 2014) their age and their experience. Experience used an ordinal scale, ranking experience from 0 years (i.e.: non-designers) to $5+$ years, in incremental steps. This data was used to create the dummy binary variable "designer", where non-design students were coded with 0 and design students (i.e.: participants indicating that they have design experience, including as students) coded as 1 . Interest in the assignment was subsequently reverse coded so higher numbers indicate more interest. Beyond this, students were also questioned about their understanding of the brief and the task.

Survey B was completed 6 times and students were reminded to do so on predefined moments. Survey B asked students about the number of users they contacted since the last time they filled out the survey, ranging from 0 to more than 7 . Following this, students were asked to specify the type of user involvement: observations, qualitative interviews, user tests, surveys, or others (with an option to add detail).

These questions were followed by a randomised list of six questions relating to students' self-confidence and motivation (Daalhuizen et al. 2014), where higher scores denote more self-confidence and lower scores more motivation. As with the results for our variable interest, motivation scores were reverse coded for the analysis to aid comprehension. For each successive day questions were individually randomised. Survey A (day 1) had 126 responses, while Survey B (day 2-7) had 350.

Prior to our analysis, we performed some data clean-up. First, we removed 11 results from persons completing the survey after the final presentation. Along with these, 2 responses were removed because they were given in the weekend, 3 duplicate entries were removed (based on ID and time), 1 incomplete result and finally, 2 entries at the start of the day before any activities. In sum, this process removed 19 entries, resulting in a complete set of $n=331$ for survey B.

Finally, we merged data from Survey A with Survey B, using the unique personal ID. In doing so, we also removed entries from students who filled out Survey B on one or more days, but failed to fill out Survey A. This merger thus left us with a total of 309 entries, completed by 108 students spread over the two-week period ( $n=78$ for day $2, n=70$ for day $3, n=62$ for day $4, n=40$ for day $5, n=36$ for day 6 and $n=23$ for day 7).

Following data clean-up, we calculated the reliability of the scales used, using Cronbach alpha $\left(\alpha_{c}\right)$. For survey A, the following $\alpha_{c}$ values were calculated: interest in the assignment $\left(\alpha_{c}=0.87\right)$, understanding of the brief: $\alpha_{c}=0.81$, understanding of the task $\left(\alpha_{c}=0.5\right)$. Neither understanding of the brief or understanding of the task was further used in this study.

For survey B, self-confidence had a $\alpha_{c}$ of 0.62 , while motivation had a score of 0.79 . Given the low $\alpha_{c}$ of self-confidence, we removed the reversed scale item for self-confidence (see

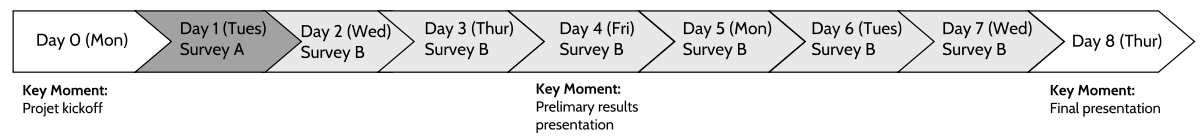

Fig. 2 Overview of days, key moments and surveys used 
"Appendix"). This resulted in an $\alpha_{c}$ of 0.66 . As a result, we proceeded with the reversed item removed.

Finally, our independent variable, user contact, is a dummy variable. To create this variable, we recoded all responses where students reported any type of user contact as 1 , with the remaining coded as 0 . We reduced this variable to a dummy because certain days contained no, or very few cases of a particular user involvement strategy and including every contact as categorical variable would result in too many independent variables given our sample size.

A potential serious concern for survey B is common method bias. This can occur when dependent and independent variables are measured using the same instrument, as is the case for survey B. For example, participants might assume a link between questions related to self-confidence and motivation and contact with end-users. Common method bias can be prevented by avoiding the use of the same instrument to measure dependent and independent variables. Risks can also be reduced by using a mix of different types of scales and measures, anchored differently (Podsakoff et al. 2003). However, given that Survey B was to be repeated daily and contained only 8 questions, our scope for doing so was limited.

Given this, we have to rely on a post hoc strategy to assess whether we have issues related to common method bias. One way of doing so is the Harman single factor test, which is an unrotated exploratory factor analysis using only one factor and including all variables. Our results show that the proportion of variance explained is 37\%, well below the recommended threshold of 50\% (Malhotra et al. 2006; Podsakoff et al. 2003). Another indication that common method bias is not likely is the absence of correlations of more than $r=0.9$ (Pavlou et al. 2007) in Survey B.

\section{Results}

\section{Sample description}

Average participant age was $21.53( \pm 4.4)$ and average interest scores was $4.60( \pm 1.3)$. A majority reported having 2 years of design experience, while the final sample also included $18.51 \%$ participants without any prior design experience. In total, $7.34 \%$ reported more than five years.

Levels of self-confidence was $4.03( \pm 1.25)$, with motivation levels at $5.49( \pm 0.99)$, where higher scores indicate more self-confidence and motivation. Overall, levels of user involvement were high, with $67 \%$ reporting some sort of user contact across the 6 measured days. Of these, qualitative interviews (65.6\%) and observations (65.2\%) were most popular. User tests $(50 \%)$ was followed by surveys $(24.6 \%)$ and the option for "others" (4.3\%) being used least often.

\section{Impact of user involvement on motivation and self-confidence}

As noted before, our data contains entries that are not independent, and we have missing data (i.e.: certain students did not fill out the survey on all days, see summary of daily participation above). Given this, it is suggested to use multilevel modelling (also referred to as random-effects models)(Field et al. 2012, p. 860; Laird and Ware 1982; Tarling 2008).

Before analysis, Field et al. (2012, p. 881) recommends assessing whether different contexts (day of measurement and students) impacts our model and whether a random-effects 
model is necessary. This is done by 1) comparing a null model where contexts are not randomised with 2) a null model containing varying contexts. This analysis finds statistically significant differences for both in the case of motivation $\left(\chi^{2}=103.15, p<0.01\right)$ and selfconfidence $\left(\chi^{2}=97.31, p<0.01\right)$. In sum, this suggests that the introduction of random intercepts for both students and days has a significant effect on our model (i.e.: varying students and days has an impact on our model)(Field et al. 2012, p. 881).

Given this, we proceed with our random effects linear model. As shown in Table 1, we include the transformed log-likelihood value ( $-2 \mathrm{LL})$, which indicates model fit. Lower values indicate better model fit but can only be compared to each successive model (i.e.: the number should not be interpreted absolutely, but relative to one another). This is accompanied by Akaike's Information Criterion index (AIC) (Akaike 1987) which also indicates model fit and can similarly only be used to compare models with one another.

To ease model comparison, we introduce three models in succession in both cases. First, we present a null model, allowing us to estimate how subsequent models fit (Model 1a and 2a). Following this, we introduce our control variables: age, interest, day of measurement and student experience (Model 1b and 2b). Day of measurement is included as categorical variable, with day 2 as reference category. Recall that during day 1 we measured our control variables age, interest and experience.

Finally, the third model (Model 1c and 2c) introduces our binary variable of interest, whether students had contact with users, presented as a binary categorical variable.

\section{Self-confidence}

Model 1a, our null-model, is followed by Model 1b, including our control variables. As seen in Table 1 , only day 4 has a significant impact on self-confidence $(B=0.35$, $p=0.02)$.

When compared with our null model, Model $1 \mathrm{~b}$ is also not significant $\left(\chi^{2}=3.5\right.$, $p=0.48$ ). Subsequent inclusion of our dependent variable, user involvement additionally fails to yield results significantly different from our null model $\left(\chi^{2}=7.71, p=0.47\right)$, with user involvement having no significant impact on self-confidence $(b=0.01$, $p=0.94)$. The lack of significant effect is also reflected in the increase of our - 2LL, and AIC values, indicating that model fit has decreased.

\section{Motivation}

Looking at student motivation, we see that of our control variables in Model $2 \mathrm{~b}$, interest has a significant positive impact on motivation $(\mathrm{B}=0.41, p<0.01)$. Model $2 \mathrm{~b}$ also significantly improves on our null model (Model 2a): $\chi^{2}=48.77, p<0.01$. Both AIC and $-2 \mathrm{LL}$ is lower than in our null model, indicating better model fit. None of the days have any significant impact (Fig. 3).

Finally including our independent variable, user involvement, we similarly find no effect $(\mathrm{B}=0.01, p=0.56)$. Correspondingly, both AIC and $-2 \mathrm{LL}$ is higher, and while Model 2c improves on our null model $\left(\chi^{2}=49.76, p=<0.01\right)$, it fails to improve on Model $2 \mathrm{~b}\left(\chi^{2}=0.93 p=0.32\right)$.

Given these results, we reject both $\mathrm{H} 1$ and $\mathrm{H} 2$. 


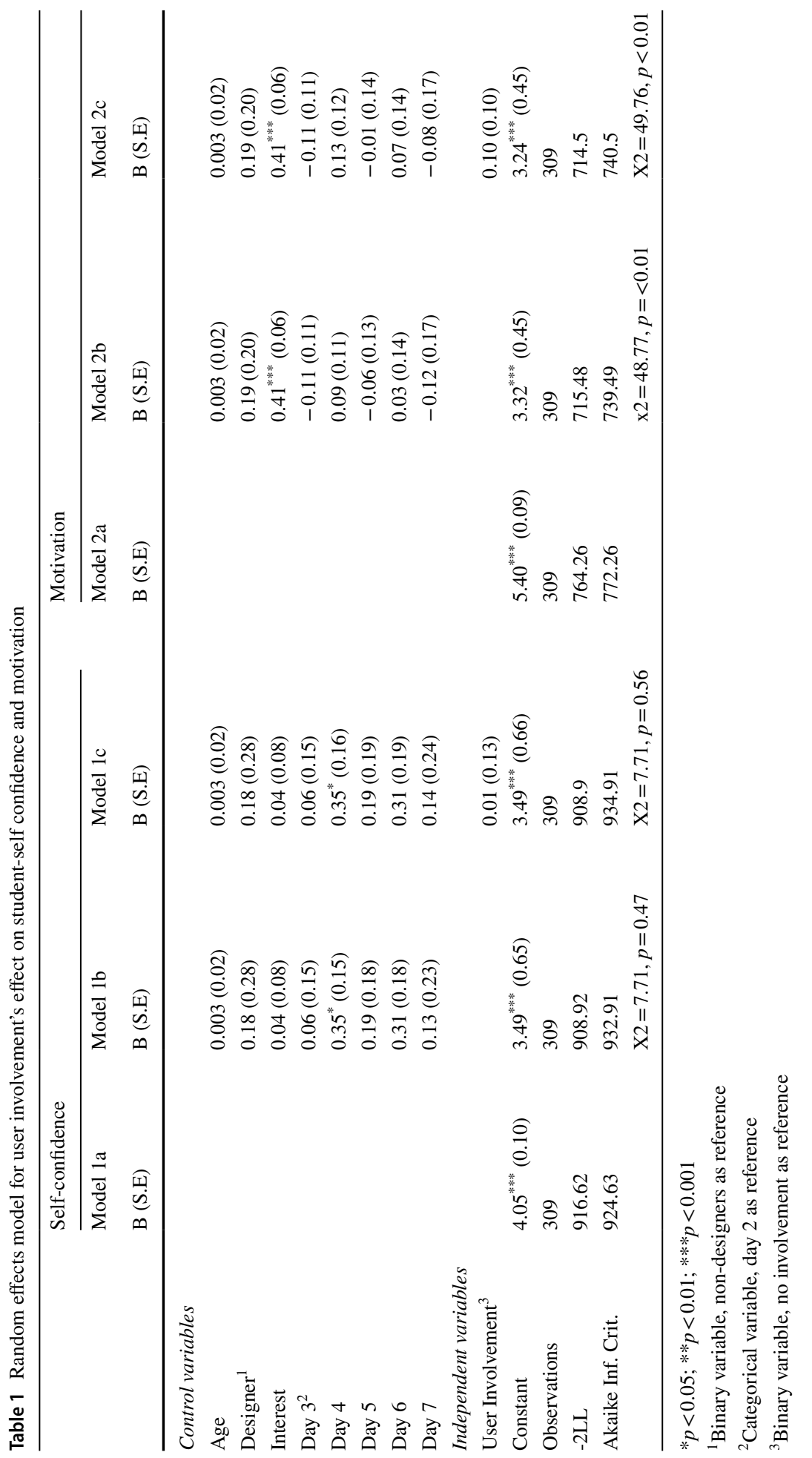




\section{Change in student motivation and self.confidence}

Shaded area indicates $95 \%$ confidence interval

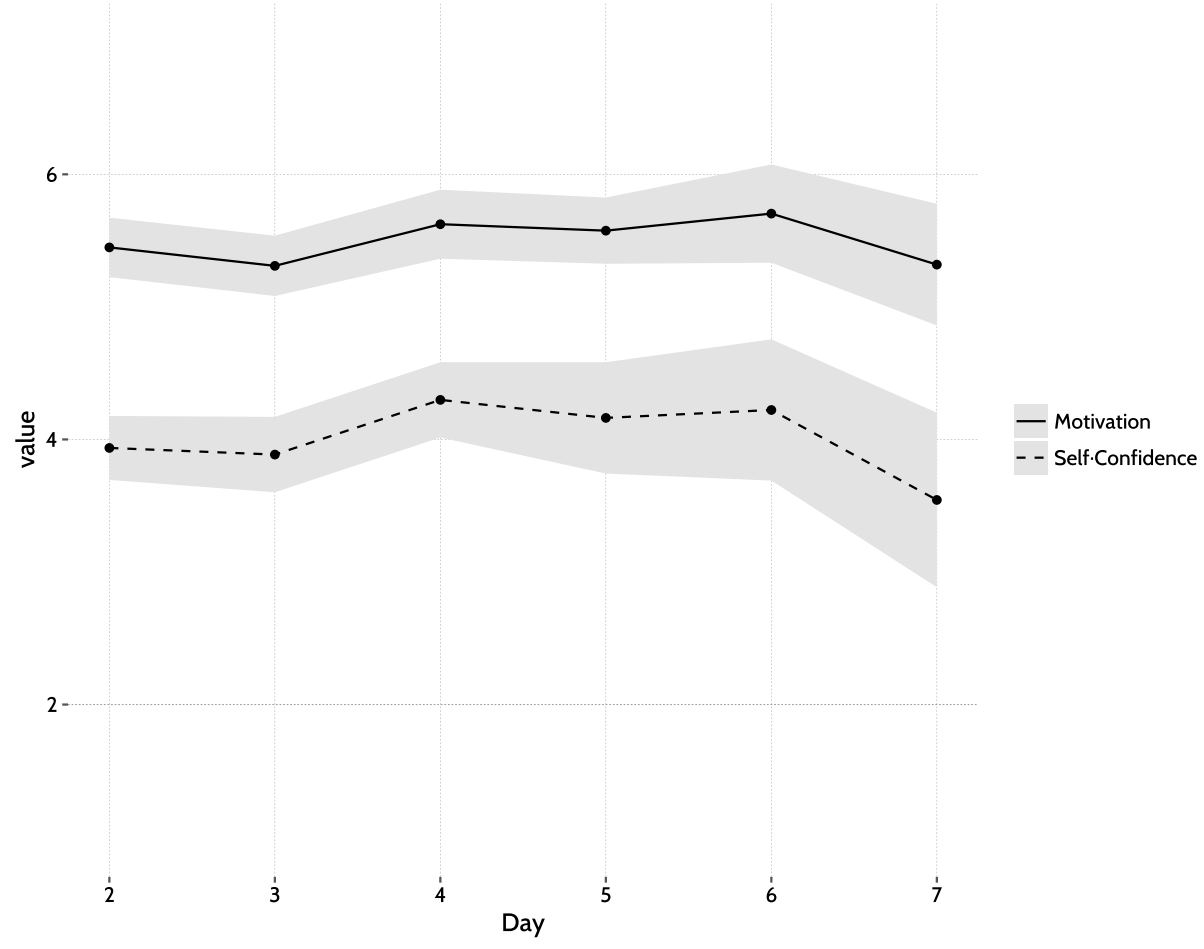

Fig. 3 Difference in self-reported motivation and self-confidence throughout the design exercise

\section{Discussion}

\section{Study limitations}

Before we discuss our findings more broadly, we note some limitations. First, our Cronbach alpha scale for self-confidence, after removal of the reversely scaled items, was slightly below the recommended level of 0.7, at 0.66 (Tavakol and Dennick 2011). As a result, the outcome of our analysis should be interpreted with caution. Additionally, while we performed post hoc evaluations to test for common method bias, finding no evidence, the fact that we combined dependent and independent variables in a single instrument is a possible cause for concern.

Our unit of analysis in this study was also the individual students. However, the overall project grade is awarded for the final group result. To ensure participant anonymity, we also did not ask the team number. It is thus possible that the student team acts as a confounding variable. In relation to this, other unmeasured factors such as frequency of consults by teachers or companies might also further influence both self-confidence and motivation. Moreover, we saw declines in student participation of the daily survey as the exercise continued. As a result, there is risk of participation bias.

Finally, we used a quantitative hypothesis-testing approach, where the effect of user involvement was statistically assessed. In contrast with qualitative studies (Gerber and 
Carroll 2012; Zoltowski et al. 2012), this approach does not allow deeper understanding of the other factors that might impact the results.

\section{Discussion}

User involvement is widely associated with system success, but little research has thus far been done on how design students experience user involvement. We measured the impact of user involvement both on student's self-reported motivation and self-confidence, controlling for prior interest, project progression as measured in days, age and experience. We find that the students who self-reported having involved a user, either through having interviewed, observed, surveyed or tested, did not feel more motivated or experience higher levels of self-confidence about the success of their design outcomes.

An unintended but valuable result of this study was the impact of prior interest. While not part of our stated research hypothesis, our results suggest that prior interest, while associated with motivation, was not associated with self-confidence, while participants with a higher interest being more motivated but not more self-confident. Finally, we find that selfconfidence was significantly higher on day 4 of measurement finding no similar effects for motivation. This increase can possibly be explained by the key moment for day 4, namely the presentation of preliminary results.

More broadly, the lack of effect found for the impact of user involvement on motivation and self-confidence presents a challenge for educators. Similar to Gerber and Caroll's (2012) assertion that prototyping increases motivation and confidence, we proposed that involving users will have similar effects. We find no evidence in our data for this.

Nonetheless, despite not finding any significant results, our study contributes to our understand of how user involvement (fails) to impact students experience during a design exercise. Generally, the uptake and value of teaching methods has been questioned (Andreasen 2011; Dorst 2008). More troubling, there is a general lack of method use in industry (Araujo et al. 1996; De Waal and Knott 2016), with user centered design adoption in practice being uneven (Mao et al. 2005).

While Kujala (2003) notes that one of the general challenges for the uptake of user involvement is highlighting it's cost-effectiveness, Bano and Zowghi (2014) argue that the benefits of user involvement cannot be calculated purely economically through return on investment. Our results suggest that from a student's perspective involving users has no measurable effect on how self-confident and motivated they report feeling during their design task. This poses questions about how the benefits of user involvement might be illustrated in an education context and points to a disconnection between the presented benefits of user involvement and how students themselves view doing so.

By design, this study was not performed in a laboratory setting. As a consequence, there were many uncaptured variables that can potentially impact both the level of self-confidence and motivation not included in our model and for which we could not and did not control. These might include the team structure and could potentially explain why no significant effects were found.

Our study also contained mostly novice designers, the majority of whom only reported 2 years of experience, which includes their current education program. It is possible that the inclusion of more experienced designers might reveal different results, notably because 
research has shown that expert designers deal differently with information gathering during design tasks (Atman et al. 2007).

Furthermore, as noted before, the involvement of users could be more characterised as viewing the user as a subject of inquiry (i.e.: involvement through interviews and observations). This can be contrasted with more in-depth involvement strategies like generative sessions. It would be of interest to assess whether more in-depth efforts might produce different results.

Finally, it is also worth considering that the relationship between information gathering through user involvement is non-linear, with Christiaan and Dorst (1992) noting that certain students get stuck during the information gathering phase, while others gathered less information initially, but proceeded to integrate their findings quicker.

\section{Future work}

We conclude with some remarks for future work. First, other variables might also be included such as use of other methods or controlling for student groups. Additionally, a two-week period might not give enough time for significant differences in both our measured outcome variables. Beyond this, future work could see the incorporation of a combination of qualitative and quantitative methods throughout design exercise to gauge student experience, with the study also being performed in a more controlled setting. More broadly, the results from this study raises general questions about the use, value and adoption of methods for user involvement, both in industry and education.

Acknowledgements The authors would like to thank all the participating students for taking the time to complete the daily surveys. We would also like to thank Wouter Durnez for the assistance in statistical modelling.

\section{Appendix: Scales and measures}

All items were 7-point Likert scales: Strongly agree (1), Agree (2), Somewhat agree (3), Neither agree nor disagree (4) Somewhat disagree (5), Disagree (6), Strongly disagree (7).

\section{Survey A (performed at the start of the study)}

Interest $\left(\alpha_{c}=0.87\right)$, scores reversed.

The topic of the design brief triggers my interest.

The design challenge posed in the design brief is interesting to me.

I find the design brief inspiring.

\section{Survey B (repeated six times)}

Self-confidence ( $\alpha_{c}=0.63, \alpha_{c}=0.66$ with reversed item removed).

I feel confident that I will be able to solve the design problem. (Reversed) (Removed).

I sometimes feel overwhelmed by the complexity of the assignment.

I doubt myself a lot when working on the assignment.

Motivation $\left(\alpha_{c}=0.79\right)$, scores reversed. 
I feel highly motivated to do this assignment.

I want to do well in this assignment.

I am working enthusiastically on this assignment.

\section{References}

Abras, C., Maloney-Krichmar, D., \& Preece, J. (2004). User-centered design. In W. Bainbridge (Ed.), Encyclopedia of human-computer interaction (Vol. 37, pp. 445-456). Thousand Oaks: Sage Publications.

Akaike, H. (1987). Factor analysis and AIC. Psychometrika, 52(3), 317-332. https://doi.org/10.1007/BF022 94359.

Andreasen, M. M. (2011). 45 Years with design methodology. Journal of Engineering Design, 22(5), 293332. https://doi.org/10.1080/09544828.2010.538040.

Araujo, C. S., Benedetto-Neto, H., Campello, A. C., Segre, F. M., \& Wright, I. C. (1996). The utilization of product development methods: A survey of UK industry. Journal of Engineering Design. https://doi. org/10.1080/09544829608907940.

Atman, C. J., Adams, R. S., Cardella, M. E., Turns, J., Mosborg, S., \& Saleem, J. (2007). Engineering design processes: A comparison of students and expert practitioners. Journal of Engineering Education, 96(4), 359-379. https://doi.org/10.1002/j.2168-9830.2007.tb00945.x.

Ball, L. J., \& Ormerod, T. C. (2000). Applying ethnography in the analysis and support of expertise in engineering design. Design Studies, 21(4), 403-421. https://doi.org/10.1016/S0142-694X(00)00009-0.

Bano, M., \& Zowghi, D. (2014). A systematic review on the relationship between user involvement and system success. Information and Software Technology. https://doi.org/10.1016/j.infsof.2014.06.011.

Barnett, S. G., Gallimore, C. E., Pitterle, M., \& Morrill, J. (2016). Impact of a paper vs virtual simulated patient case on student-perceived confidence and engagement. American Journal of Pharmaceutical Education, 80(1), 16. https://doi.org/10.5688/ajpe80116.

Baroudi, J. J., Olson, M. H., \& Ives, B. (1986). An empirical study of the impact of user involvement on system usage and information satisfaction. Communications of the ACM, 29(3), 232-238. https://doi. org/10.1145/5666.5669.

Beckman, S. L., \& Barry, M. (2007). Innovation as a learning process: Embedding design thinking. California Management Review, 50(1), 25-56. https://doi.org/10.2307/41166415.

Button, G. (2000). The ethnographic tradition and design. Design Studies, 21(4), 319-332. https://doi. org/10.1016/S0142-694X(00)00005-3.

Christiaans, H., \& Dorst, K. (1992). Cognitive models in industrial design engineering. Design Theory and Methodology, 42(August), 131-140.

Conradie, P., De Marez, L., \& Saldien, J. (2017). User consultation during the fuzzy front end: Evaluating student's design outcomes. International Journal of Technology and Design Education, 27(4), 563575. https://doi.org/10.1007/s10798-016-9361-4.

Cross, N. (2004). Expertise in design: An overview. Design Studies, 25(5), 427-441. https://doi. org/10.1016/j.destud.2004.06.002.

Cross, N. (2008). Engineering design methods: Strategies for product design. Design (3rd ed., Vol. 1). New York: Wiley.

Daalhuizen, J., Person, O., \& Gattol, V. (2014). A personal matter? An investigation of students' design process experiences when using a heuristic or a systematic method. Design Studies, 35(2), 133-159. https ://doi.org/10.1016/j.destud.2013.10.004.

De Waal, G. A., \& Knott, P. (2016). Patterns and drivers of NPD tool adoption in small high-technology firms. IEEE Transactions on Engineering Management, 63(4), 350-361. https://doi.org/10.1109/ TEM.2016.2603160.

Denton, H., \& McDonagh, D. (2003). Using focus group methods to improve students' design project research in schools: Drawing parallels from action research at undergraduate level. International Journal of Technology and Design Education, 13(2), 129-144. https://doi.org/10.1023/A:1024149703800.

Dorst, K. (2008). Design research: A revolution-waiting-to-happen. Design Studies, 29(1), 4-11. https://doi. org/10.1016/j.destud.2007.12.001.

Dubberly, H., \& Evenson, S. (2011). Design as learning-or "knowledge creation"- the SECI model. Interactions, 18(1), 75. https://doi.org/10.1145/1897239.1897256.

Field, A., Miles, J., \& Field, Z. (2012). Discovering statistics using R (Vol. 58). Statistics. https://doi. org/10.1111/insr.12011_21. 
Gerber, E. (2009). Prototyping: facing uncertainty through small wins. In International conference on engineering design (pp. 333-342). Stanford.

Gerber, E., \& Carroll, M. (2012). The psychological experience of prototyping. Design Studies, 33(1), 64-84. https://doi.org/10.1016/j.destud.2011.06.005.

Giacomin, J. (2014). What is human centred design? Design Journal, 17(4), 606-623. https://doi. org/10.2752/175630614X14056185480186.

Günther, J., \& Ehrlenspiel, K. (1999). Comparing designers from practice and designers with systematic design education. Design Studies, 20(5), 439-451. https://doi.org/10.1016/S0142-694X(99)00019 -8 .

Hanington, B. (2003). Methods in the making: A perspective on the state of human research in design. Design Issues, 19(4), 9-18. https://doi.org/10.1162/074793603322545019.

Hanington, B., \& Martin, B. (2012). Universal methods of design: 100 ways to research complex problems. Develop Innovative Ideas: Rockport Publishers.

IDEO. (2018). Design kit: The human-centered design toolkit. Retrieved June 12, 2018, from https:// www.ideo.com/post/design-kit

ISO. (2002). ISO/TR 16982:2002: Ergonomics of human-system interaction-usability methods supporting human-centred design. Geneva: Switzerland.

ISO. (2015). International standard for human-centred design of interactive systems - ISO 9241210:2010. Geneva: Switzerland.

Ives, B., \& Olson, M. H. (1984). User involvement and MIS success: A review of research. Management Science, 30(5), 586-603. https://doi.org/10.1287/mnsc.30.5.586.

Karat, C. M. (1994). A comparison of user interface evaluation methods. In Usability inspection methods (pp. 203-233). Wiley.

Karat, J. (1997). Evolving the scope of user-centered design. Communications of the ACM, 40(7), 33-38. https://doi.org/10.1145/256175.256181.

Kaulio, M. A. (1998). Customer, consumer and user involvement in product development: A framework and a review of selected methods. Total Quality Management, 9(1), 141-149. https://doi. org/10.1080/0954412989333.

Klapwijk, R., \& Van Doorn, F. (2015). Contextmapping in primary design and technology education: A fruitful method to develop empathy for and insight in user needs. International Journal of Technology and Design Education, 25(2), 151-167. https://doi.org/10.1007/s10798-014-9279-7.

Klemmer, S., \& Coursera. (2019). Human-centered design: An introduction. Retrieved from https:// www.coursera.org/learn/human-computer-interaction

Kujala, S. (2003). User involvement: A review of the benefits and challenges. Behaviour \& Information Technology, 22(1), 1-16. https://doi.org/10.1080/0144929021000055530.

Laird, N. M., \& Ware, J. H. (1982). Random-effects models for longitudinal data. Biometrics, 10, 10. https://doi.org/10.2307/2529876.

Lawson, B., \& Dorst, K. (2009). Design expertise. London: Taylor \& Francis. Retrieved from http:// www.amazon.com/Design-Expertise-Bryan-Lawson/dp/1856176703

Malhotra, N. K., Kim, S. S., \& Patil, A. (2006). Common method variance in IS research: A comparison of alternative approaches and a reanalysis of past research. Management Science, 52(12), 18651883. https://doi.org/10.1287/mnsc.1060.0597.

Mao, J.-Y., Vredenburg, K., Smith, P. W., \& Carey, T. (2005). The state of user-centered design practice. Communications of the ACM, 48(3), 105-109. https://doi.org/10.1145/1047671.1047677.

Morgan, A., \& Jones, D. (2009). Perceptions of service user and carer involvement in healthcare education and impact on students' knowledge and practice: A literature review. Medical Teacher, 31(2), 82-95. https://doi.org/10.1080/01421590802526946.

Norman, D. A. (2013). The design of everyday things. Human Factors and Ergonomics in Manufacturing, 10, 10. https://doi.org/10.1002/hfm.20127.

Pahl, G., Beitz, W., Feldhusen, J., \& Grote, K.-H. (2007). Engineering design: A systematic approach. London, UK: Springer.

Pavlou, P. A., Liang, H., \& Xue, Y. (2007). Understanding and mitigating uncertainty in online exchange relationships: A principal-agent perspective. MIS Quarterly, 31(1), 105. https://doi. org/10.2307/25148783.

Podsakoff, P. M., Mackenzie, S. B., Lee, J., \& Podsakoff, N. P. (2003). Common Method Biases in Behavioral Research: A Critical Review of the Literature and Recommended Remedies. Journal of applied psychology, 88(5), 879-903. https://doi.org/10.1037/0021-9010.88.5.879.

Rapanta, C., \& Cantoni, L. (2014). Being in the users' shoes: Anticipating experience while designing online courses. British Journal of Educational Technology, 45(5), 765-777. https://doi.org/10.1111/ bjet. 12102 . 
Sanders E. B. N., \& Stappers, P. J. (2013). Convivial design toolbox: Generative research for the front end of design. London: British Interplanetary Society. Retrieved from http://books.google.com/books $?$ id $=$ a8miuAAACAAJ \&pgis $=1$

Tarling, R. (2008). Statistical modelling for social researchers: Principles and practice. Routledge.

Tavakol, M., \& Dennick, R. (2011). Making sense of Cronbach's alpha. International Journal of Medical Education, 2, 53-55. https://doi.org/10.5116/ijme.4dfb.8dfd.

Tolkamp, J., Huijben, J. C. C. M., Mourik, R. M., Verbong, G. P. J., \& Bouwknegt, R. (2018). User-centred sustainable business model design: The case of energy efficiency services in the Netherlands. Journal of Cleaner Production, 182, 755-764. https://doi.org/10.1016/j.jclepro.2018.02.032.

Trischler, J., Pervan, S. J., Kelly, S. J., \& Scott, D. R. (2018). The value of codesign: the effect of customer involvement in service design teams. Journal of Service Research, 21(1), 75-100. https://doi. org/10.1177/1094670517714060.

Wood, J., \& Wilson-Barnett, J. (1999). The influence of user involvement on the learning of mental health nursing students. NT Research, 4(4), 257-270. https://doi.org/10.1177/136140969900400403.

Wormald, P. W. (2011). Positioning industrial design students to operate at the "fuzzy front end": Investigating a new arena of university design education. International Journal of Technology and Design Education, 21(4), 425-447. https://doi.org/10.1007/s10798-010-9133-5.

Zoltowski, C. B., Oakes, W. C., \& Cardella, M. E. (2012). Students' ways of experiencing human-centered design. Journal of Engineering Education, 101(1), 28-59. https://doi.org/10.1002/j.2168-9830.2012. tb00040.x.

Publisher's Note Springer Nature remains neutral with regard to jurisdictional claims in published maps and institutional affiliations. 